J. Lake Sci. (湖泊科学), 2012, 24(5): 712-716

http: //www. jlakes. org. E-mail : jlakes@niglas.ac.cn

(C) 2012 by Journal of Lake Sciences

\title{
太湖浮游植物细胞裂解速率的酯酶活性法初步研究
}

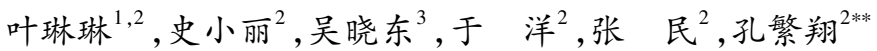 \\ ( 1 : 南通大学地理科学学院, 南通 226019) \\ (2: 中国科学院南京地理与湖泊研究所湖泊与环境国家重点实验室,南京 210008) \\ (3:中国科学院寒区早区环境与工程研究所,兰州 730000)
}

摘 要: 本研究从 2009 年 8 月至 2010 年 10 月,每月采集太湖 3 个不同富营养化湖区水样,运用酯酶活性法,测定了颗粒 态酯酶、溶解性酯酶活性以及酯酶衰变周期,估算了太湖浮游植物细胞裂解速率. 研究结果表明,太湖颗粒态酯酶活性为 $0.58 \sim 35.15 \mathrm{nmol} \mathrm{FDA} /(\mathrm{L} \cdot \mathrm{h})$, 溶解性酯酶活性为 $0.55 \sim 7.59 \mathrm{nmol} \mathrm{FDA} /(\mathrm{L} \cdot \mathrm{h})$, 酯酶衰变周期为 $7 \sim 75 \mathrm{~h}$, 细胞裂解 速率为 $0.02 \sim 0.77 \mathrm{~d}^{-1}$, 三个采样点细胞裂解速率没有显著差异. 颗粒态酯酶活性与叶绿素 a 浓度之间具有显著的线性 关系, 说明运用酯酶活性法估算太湖浮游植物细胞裂解速率是可行. 此外, 叶绿素 a 浓度与温度变化趋势基本一致,梅梁 湾和湖心叶绿素 a 浓度具有显著差异. 贡湖湾叶绿素 a 浓度与细胞裂解速率之间具有显著的反比例关系, 说明细胞裂解 速率也是影响太湖藻类生物量的重要因素.

关键词: 酯酶活性; 太湖; 细胞裂解速率; 浮游植物

\section{Assessing phytoplankton cell lysis rate in Lake Taihu by esterase assay}

\author{
YE Linlin ${ }^{1,2}$, SHI Xiaoli ${ }^{2}$, WU Xiaodong ${ }^{3}$, YU Yang ${ }^{2}$, ZHANG Min ${ }^{2} \&$ KONG Fanxiang ${ }^{2}$ \\ (1: Geographical Sciences College, Nantong University, Nantong 226019, P. R. China) \\ (2: State Key Laboratory of Lake Science and Environment, Nanjing Institute of Geography and Limnology, Chinese Academy \\ of Sciences, Nanjing 210008, P. R. China) \\ (3: Cold and Arid Regions Environmental and Engineering Research Institute, Chinese Academy of Sciences, Lanzhou 730000 , \\ P. R. China)
}

\begin{abstract}
Phytoplankton lysis rate in three different eutrophic regions of Lake Taihu was measured by the activities of particle and dissolved esterase, as well as the decay rate of the latter, from August 2009 to October 2010. The present results showed that the particulate, dissolved esterase activity, half life time of dissolved esterase, and cell lysis rates ranged from 0.58 - 35. $15 \mathrm{nmol}$ $\mathrm{FDA} /(\mathrm{L} \cdot \mathrm{h}), 0.55-7.59 \mathrm{nmol} \mathrm{FDA} /(\mathrm{L} \cdot \mathrm{h}), 7-75 \mathrm{~h}$, and $0.02-0.77 \mathrm{~d}^{-1}$, respectively. No significant differences were found in the cell lysis rates among the three sampling sites. The significant linear relationship between Chl.a concentration and particulate esterase activities suggests that it is feasible to assess phytoplankton cell lysis rate in Lake Taihu by the esterase assay. Furthermore, Chl.a concentration showed the same pattern with water temperature, a significant difference was observed in Chl.a concentration between Meiliang Bay and lake centre. The strong, negative correlation between Chl.a concentration and lysis rate in Gonghu Bay suggests that phytoplankton biomass was affected by the lysis rate in Lake Taihu.
\end{abstract}

Keywords: Esterase assay; Lake Taihu; cell lysis rate; phytoplankton

浮游动物的捕食和沉降被认为是浮游植物生物量减少的最主要原因 ${ }^{[1]}$. 近年来研究发现藻类细胞裂解 也是藻类生物量减少的重要原因,细胞裂解会影响到藻的生长变化和微生物群落结构演替,并进而影响到

* 国家重点基础研究发展计划 “973” 项目 (2008CB418005,2008CB418000) 和国家自然科学基金项目 (41001032, 40901268) 联合资助. 2011-10-14 收稿;2011-11-13 收修改稿. 叶琳琳,女, 1981 年生, 博士, 助教; E-mail: yelinlin8164@163.com.

** 通信作者;E-mail:fxkong@ niglas. ac. cn. 
食物网中的物质循环过程 ${ }^{[2-3]}$.

Van Boekel 等 ${ }^{[2]}$ 最先提出酯酶活性方法, 指出藻细胞在裂解的过程中溶解性酯酶会释放到水体里, 可利 用水体中溶解性酯酶活性的变化来估算自然界中藻细胞的裂解速率. 在海洋中运用酯酶活性为指标研究藻 细胞裂解已经取得了大量成果 ${ }^{[4-5]}$, 北海球形棕囊藻的消亡就是由细胞裂解所引起 ${ }^{[2-3]}$. 北大西洋浮游植物 细胞裂解释放的藻源性溶解性有机碳在初级生产力中的比例高达 $30 \% \sim 70 \%{ }^{[6]}$. 但是到目前为止, 关于淡水 湖泊中藻的细胞裂解速率的研究还很少, 我们对太湖浮游植物细胞裂解速率的季节性变化规律以及细胞裂 解可能对藻类生物量的影响还不清楚. 本研究采用酯酶活性方法, 定量计算太湖 3 个不同富营养化湖区浮 游植物细胞裂解速率, 探讨温度、叶绿素浓度与浮游植物细胞裂解速率之间的可能关系.

\section{1 材料与方法}

\section{1 采样点设置}

太湖是长江中下游地区五大淡水湖之一, 实际水域 面积 $2338.1 \mathrm{~km}^{2}$, 平均水深 $1.9 \mathrm{~m}$, 最大水深 $2.6 \mathrm{~m}^{[7]}$. 采 样时间为 2009 年 8 月- 2010 年 10 月,每月采集 1 次 混合水样, 采样点包括梅梁湾, 湖心和贡湖湾 (图 1). 梅梁湾和贡湖湾是太湖的典型湖区, 前者属典 型的藻型湖区,后者部分水域有水草分布. 湖心受 外源污染物影响比较小.

\section{2 酯酶活性的测定}

运用酯酶活性法确定藻类细胞裂解速率需要 测定 3 个参数 ${ }^{[4]}$ : 藻细胞内酯酶一一颗粒态酯酶活 性(Particulate Esterase Activity, PEA)、水中溶解性 酯酶活性 (Dissolved Esterase Activity, DEA)、溶解 性酯酶的衰变周期 $\left(T_{1 / 2}\right)$.

1.2.1PEA 和 DEA 的测定 取 $100 \sim 250 \mathrm{ml}$ 水样过

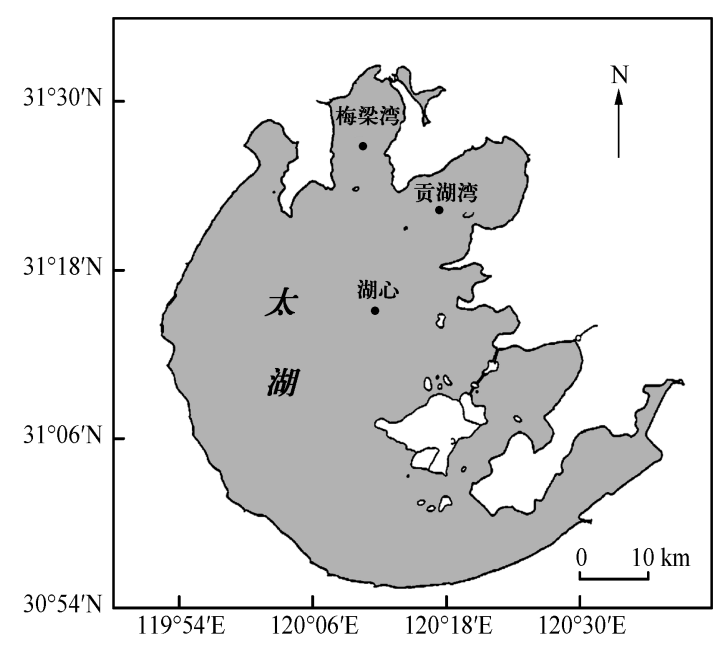

图 1 太湖采样点设置

Fig. 1 Location of sampling sites in Lake Taihu 滤到 Whatman GF/C 滤膜上, 用 $0.1 \mathrm{~mol} / \mathrm{L}$ 磷酸缓冲液 $(\mathrm{pH}=7.8)$ 研磨, 离心后取上清液 $4 \mathrm{ml}$, 与 $950 \mu \mathrm{l}$ $0.1 \mathrm{~mol} / \mathrm{L}$ 磷酸缓冲液和 $50 \mu \mathrm{l} 2.5 \mathrm{mmol} / \mathrm{L} \mathrm{FDA}$ 混合, 使得 $\mathrm{FDA}$ 终浓度为 $25 \mu \mathrm{mol} / \mathrm{L}$. 黑暗处 $30^{\circ} \mathrm{C}$ 培养 $1 \mathrm{~h}$ 测定 ${ }^{[8]}$. FDA 在酯酶作用下裂解, 其裂解产物能够定量地发出苂光. 使用苂光光度计 ( RF-5301 PC, 日本岛 津) 测定, 激发波长 $490 \mathrm{~nm}$, 发射波长 $520 \mathrm{~nm}$. 使用苂光素 (fluorescein, Sigma \# 46955) 做标准曲线, 酯酶活 性的单位为 $\mathrm{nmol} \mathrm{FDA} /(\mathrm{L} \cdot \mathrm{h}) . D E A$ 测定取过滤后水样 $(4 \mathrm{ml})$, 具体方法与 $P E A$ 相同.

1.2.2 酯酶衰变常数的测定 酯酶衰变常数按 Agustí 等 ${ }^{[4]}$ 的方法测定. 即取 $0.2 \mu \mathrm{m}$ (Millipore) 滤膜过滤后 的水样加人 $250 \mu \mathrm{l}$ 稀释 1000 倍的猪肝酯酶 (Porcine esterase, Sigma \# 2884), 在室温条件下于黑暗处培养 1 周, 每天取水样测定溶解性酯酶活性.

\section{3 细胞裂解速率的计算}

细胞裂解速率 $(L R)$ 通过颗粒态酯酶活性相对于时间的变化来计算:

$$
u_{\mathrm{L}}=\ln \left(\frac{P E A_{t}}{P E A_{0}}\right) / t
$$

式中, $P E A_{0}$ 为初始状态颗粒态酷酶活性; $P E A_{t}$ 为经过 $t$ 时间后颗粒态酯酶活性, 等于 $P E A_{0}$ 减去这段时间间隔 中产生的溶解性酯酶 $E A_{\text {(prod) }}$.

溶解性酯酶的衰变常数 $\left(u(l o s s)_{\mathrm{EA}}, \mathrm{h}^{-1}\right)$ 计算公式为:

$$
u(\operatorname{loss})_{\mathrm{EA}}=\ln \left(\frac{E A_{0}}{E A_{t}}\right) / t
$$

式中, $E A_{0}$ 为加人猪肝酯酶后初始状态水中溶解性醌酶活性; $E A_{t}$ 为加人猪肝酯酶 $t$ 时间后水中溶解性酯酶活 
性; 酯酶的衰变常数 (单位为 $h$ ) 为:

$$
T_{1 / 2}=\ln 0.5 / u(\operatorname{loss})_{\mathrm{EA}}
$$

$E A_{(\text {prod) }}$ 为每小时产生的溶解性酯酶:

$$
E A_{(\text {prod })}=\frac{1}{2} E A / T_{1 / 2}
$$

式中, $E A$ 为初始时水中溶解性酯酶活性 (单位为 $\mathrm{nmol} \mathrm{FDA} /(\mathrm{L} \cdot \mathrm{h})$ ).

浮游植物细胞裂解速率 (单位为 $\left.\mathrm{h}^{-1}\right)$ 计算公式为:

$$
u_{\mathrm{L}}=\ln \left(\frac{P E A_{0}-P E A_{(\text {prod) }}}{P E A_{0}}\right) / t
$$

$u_{\mathrm{L}}$ 乘以 $24 \mathrm{~h}$,可以换算成单位为 $\mathrm{d}^{-1}$.

\section{4 叶绿素 $\mathrm{a}(\mathrm{Chl} . \mathrm{a})$ 浓度的测定}

水样 (100 250 ml) 经 Whatman $\mathrm{GF} / \mathrm{C}$ 滤膜过滤后, 加人 $90 \%$ 丙酥研磨, $4^{\circ} \mathrm{C}$ 黑暗条件下静置 $8 \sim 10 \mathrm{~h}$, 离 心, 用 $90 \%$ 丙酮定容, 用苂光光度计测定, 激发波长 $350 \mathrm{~nm}$, 发射波长 $670 \mathrm{~nm}$.

\section{2 结果和讨论}

\section{1 叶绿素 $\mathrm{a}$ 浓度与温度的变化}

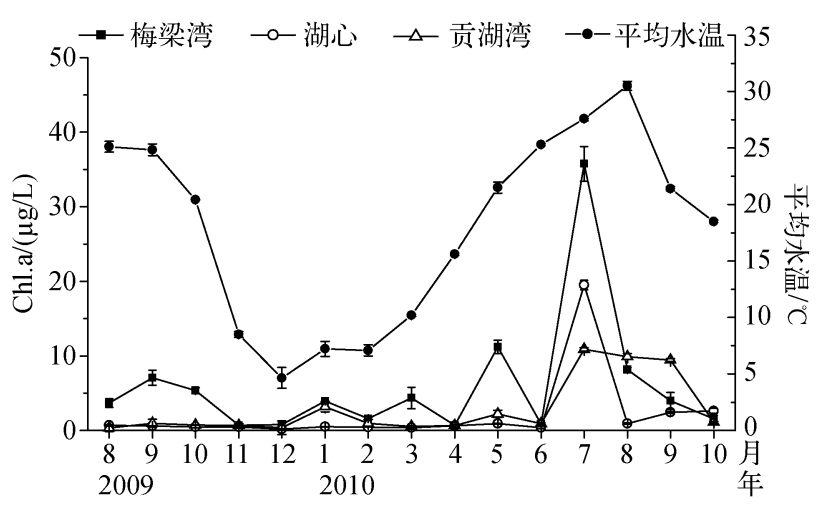

图 2 太湖叶绿素 $\mathrm{a}$ 和水温变化

Fig. 2 Variation of Chl.a concentration and average water temperature in Lake Taihu

在整个研究阶段,梅梁湾和湖心叶绿 素 a 浓度具有显著差异 $(n=15, P=$ $0.006)$. 太湖是大型浅水湖泊, 风场对藻类 的时空分布具有重要影响. 太湖藻类在北 部湖区如梅梁湾等水域聚集, 形成严重水 华, Chen 等 ${ }^{[9]}$ 也在太湖发现相同的藻类空 间分布规律. 三个采样点叶绿素 a 浓度都 在 2010 年 7 月达到最大值, 分别为 $36 \pm 2$ 、 $20 \pm 1 、 11 \pm 2 \mu \mathrm{g} / \mathrm{L}$. 梅梁湾叶绿素 a 浓度 在 2009 年 11 月出现最低值 $(0.7 \pm$ $0.1 \mu \mathrm{g} / \mathrm{L})$, 湖心和贡湖湾都在 2009 年 12 月出现最低值, 分别为 $0.19 \pm 0.02 、 0.37 \pm$ $0 \mu \mathrm{g} / \mathrm{L}$. 三个采样点水温没有显著差异, 平 均水温在 2010 年 8 月出现最大值 $31^{\circ} \mathrm{C}$, 2009 年 11 月出现最低水温 $4.7^{\circ} \mathrm{C}$, 其中

2009 年 9 月和 11 月,平均水温分别低于 25 和 $15^{\circ} \mathrm{C}$ (图 2). 温度是影响藻类生物量的重要因素,水温高于 $25^{\circ} \mathrm{C}$ 有利于藻类大量生长繁殖. 本研究没有对藻类群落结构进行分析, 但是太湖藻类水华主要群落是蓝藻, 而有文献报道当水温低于 $15^{\circ} \mathrm{C}$ 时, 蓝藻停止生长和繁殖 ${ }^{[0]}$. 研究发现叶绿素 $\mathrm{a}$ 浓度与水温变化趋势基本一 致,伴随着温度降低,叶绿素 a 浓度在 2009 年 8-11 月和 2010 年 8-10 月迅速降低;2010 年 3-7 月,伴随 着水温升高, 叶绿素 a 浓度显著升高.

\section{2 细胞裂解速率的变化}

三个点位 $P E A$ 在 2009 年 8 月- 2010 年 1 月以及 2010 年 8-10 月迅速降低 (图 3a), 这两个阶段由于水 温开始降低,浮游植物细胞开始裂解, 所以颗粒态醌酶活性迅速减少转变成溶解性酯酶. 而 2010 年 3-7 月 $P E A$ 迅速增加, 在此期间由于温度升高, 藻类生长繁殖, 因此藻内细胞酯酶活性较高. 研究发现 $P E A$ 与叶绿 素 a 浓度具有显著的线性关系: $P E A=0.67 \mathrm{Chl} . \mathrm{a}+6.75\left(R^{2}=0.26, n=45, P<0.001\right)$. 这在一定程度上验证 了用酯酶活性来表征藻类的生理活性,进而计算浮游植物细胞裂解速率是可行的方法.

溶解性酯酶活性在 2009 年 8-10 月间维持在一个较高的水平波动, 主要是来源于藻类细胞裂解. 此外, 
2010 年 4 月, 梅梁湾和湖心 $D E A$ 出现峰值, 分别为 $2.20 \pm 0.06 、 3.6 \pm 0.03 \mathrm{nmol} \mathrm{FDA} /(\mathrm{L} \cdot \mathrm{h}), 2010$ 年 6 月, 贡湖湾 $D E A$ 出现峰值, 为 $3.4 \pm 0.01 \mathrm{nmol} \mathrm{FDA} /(\mathrm{L} \cdot \mathrm{h})$ (图 $3 \mathrm{~b}$ ).

3 个点位酯酶衰变常数没有显著差异, 梅梁湾酯酶衰变周期为 $10 \sim 75 \mathrm{~h}$, 湖心为 $7 \sim 44 \mathrm{~h}$, 贡湖湾为 $8 \sim$ $62 \mathrm{~h}$ (图 $3 \mathrm{c}$ ). Berman 等 ${ }^{[8]}$ 研究发现从藻类细胞提取的酯酶以及商品酯酶的衰变周期不存在差异. 在 Kinneret 湖表层水体中添加商品酯酶, 培育的温度范围为 $15 \sim 30^{\circ} \mathrm{C}$, 酯酶的衰败常数为 $0.03 \sim 0.49 \mathrm{~h}^{-1}$. Riegman 等 ${ }^{[11]}$ 研究发现北海经过过滤后的水体中添加从浮游植物体内提取的酯酶, 其衰变周期为 $49 \mathrm{~h}$, 而添加商品酯酶, 其衰变周期为 $31 \mathrm{~h}$.

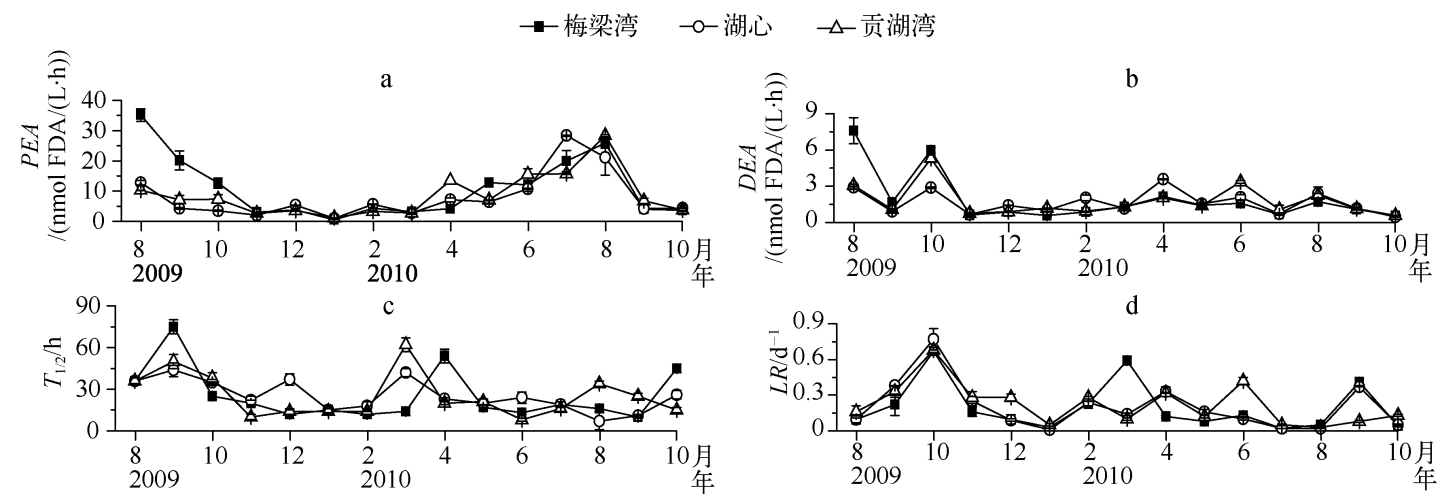

图 3 颗粒态酯酶、溶解态酯酶、酯酶衰变周期和细胞裂解速率

Fig. 3 Variation of particulate esterase assay, disslove eserase assay, half life time of dissolve esterase assay and phytoplankton cell lysis rate

梅梁湾细胞裂解速率在 2009 年 10 月、2010 年 3 月以及 9 月出现三个峰值, 分别为 $0.67 、 0.59 、 0.41 \mathrm{~d}^{-1}$. 湖心 细胞裂解速率在 2009 年 10 月、2010 年 4 月、9 月出现三个峰值, 分别为 $0.77 、 0.33 、 0.37 \mathrm{~d}^{-1}$. 贡湖湾细胞裂 解速率在 2009 年 10 月以及 2010 年 6 月出现两次峰值, 分别为 $0.68 、 0.42 \mathrm{~d}^{-1}$ (图 $3 \mathrm{~d}$ ). 已有的研究发现水 温是影响细胞裂解速率的一个重要因素, 细胞裂解速率一般冬天较低 $\left(<0.1 \mathrm{~d}^{-1}\right)$, 春季水华结束后较高, 约 为 $0.3 \mathrm{~d}^{-1[12]}$. 北海浮游植物细胞春季裂解速率为 $0.01 \sim 0.25 \mathrm{~d}^{-1[13]}$, 夏季维持在一个较高的水平 $(0.05 \sim$ $\left.0.30 \mathrm{~d}^{-1}\right)$. Hayakawa 等 ${ }^{[14]}$ 在太平洋西北部发现藻的细胞裂解速率在夏季末期是 $0.12 \sim 0.67 \mathrm{~d}^{-1}$. 此外, 3 个采样点都在 2009 年 10 月出现峰值, 而其中 2 个采 样点都在 2010 年 9 月出现峰值. 本研究认为水华后 期, 藻类细胞可能由于营养盐耗竭产生大量裂解, 而 在水华期间藻类细胞内存储了大量营养物质, 细胞 裂解的过程就是这些营养盐从颗粒态向溶解态的一 个转变过程, 因此细胞裂解会对水体中营养元素循 环有重要影响.

藻类的生物量可以用生长速率和死亡速率来表 示, 因此水华不同阶段的细胞裂解速率可能是影响叶 绿素浓度的一个重要因素. Berman 等 ${ }^{[8]}$ 研究发现藻类 生物量和细胞裂解速率之间存在反比例的关系. 同 样, Agustí 等 ${ }^{[15]}$ 在佛罗里达的 7 个湖泊中运用了酶消 解法计算藻细胞死活比,结果发现活细胞与叶绿素 a 浓 度之间呈正相关, 表明叶绿素 a 浓度与细胞裂解速率之 间具有负相关关系. 本研究发现, 贡湖湾细胞裂解速率 与叶绿素 a 浓度之间具有显著的反比例关系(图 4), 表

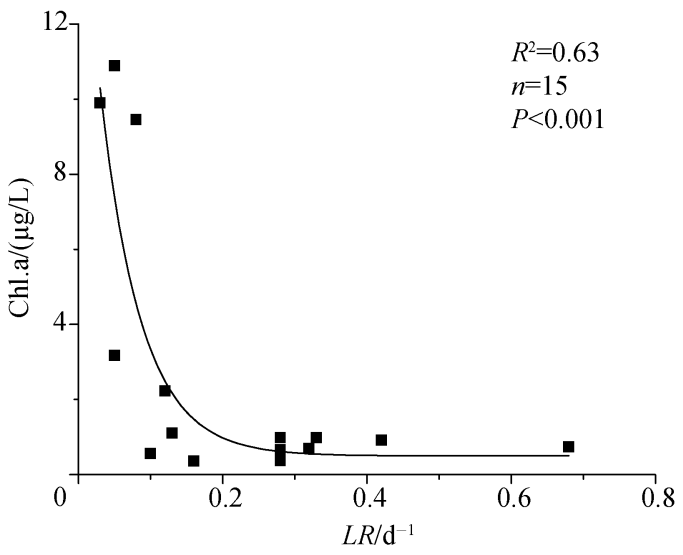

图 4 贡湖湾浮游植物细胞裂解速率与 叶绿素 a 浓度之间的关系

Fig. 4 Relationship between cell lysis rate of phytoplankton and Chl.a concentration in Gonghu Bay 
明细胞裂解速率是影响叶绿素 a 浓度的重要因素.

运用酯酶活性法可以估算太湖浮游植物细胞裂解速率,这对于探讨藻类水华在消亡过程中营养元素的 释放具有重要的价值. 太湖浮游植物细胞裂解速率在水华形成阶段具有明显的差异,这种差异的影响因素 还需要后续研究来深人探讨.

致谢: 感谢采样过程中季江、阳振老师, 李大命、贾育红、蔡元锋博士的帮助.

\section{3 参考文献}

[ 1 ] Tijdens M, Van De Wall DB, Slovackova H et al. Estimates of bacterial and phytoplankton mortality caused by viral lysis and microzooplankton grazing in a shallow eutrophic lake. Freshwater Biology, 2008, 53 : 1126-1141.

[ 2 ] Van Boekel WHM, Hansen FC, Riegman R et al. Lysis-induced decline of a Phaeocystis spring bloom and coupling with the microbial foodweb. Marine Ecology Progress Series, 1992, 81:269-276.

[ 3 ] Brussaard CPD, Riegman R, Noordeloos AAM et al. Effects of grazing, sedimentation and phytoplankton cell lysis on the structure of a coastal pelagic food web. Marine Ecology Progress Series, 1995, 123 :259-271.

[ 4 ] Agustí S, Satta MP, Mura MP et al. Dissolved esterase activity as a tracer of phytoplankton lysis: evidence of high phytoplankton lysis rates in the northwestern Mediterranean. Limnology and Oceanography, 1998, 43(8) : 1836-1849.

[ 5 ] Agustí S, Sánchez MC. Cell viability in natural phytoplankton communities quantified by a membrane permeability probe. Limnology and Oceanography, 2002, 47 (3):818-828.

[ 6 ] Agustí S, Duarte CM, Vaque D et al. Food-web structure and elemental ( C, N and P) fluxes in the eastern tropical North Atlantic. Deep-Sea Res II, 2001, 48: 2295-2321.

[ 7 ] 秦伯强,胡维平,陈伟民等. 太湖水环境演化过程与机理. 北京:科学出版社,2004:1-3.

[ 8 ] Berman T, Wynne D. Assessing phytoplankton lysis in Lake Kinneret. Limnology and Oceanography, 2005, 50 (2) : 526537.

[ 9 ] Chen YW, Qin BQ, Teubner K et al. Long-term dynamics of phytoplankton assemblages: Microcystis-domination in Lake Taihu, a large shallow lake in China. Journal of Plankton Research, 2003, 25(1) :445-453.

[10] Robarts RD, Zohary T. Temperature effects on photosynthetic capacity, respiration, and growth rates of bloom-forming cyanobacteria. New Zealand Journal of Marine and Freshwater Research, 1987, 21 : 391-399.

[11] Riegman R, Van Bleijswijk JDL, Brussaard CPD. The use of dissolved esterase activity as a tracer of phytoplankton lysis. Limnology and Oceanography, 2002, 47(3) : 916-920.

[12] Riegman R, Winter C. Lysis of plankton in the non-stratified southern North Sea during summer and autumn 2000. Acta Oecologica, 2003, 24 : S133-S138.

[13 Agustí S, Duarte CM. Strong seasonality in phytoplankton cell lysis in the NW Mediterranean littoral. Limnology and Oceanography, 2000, 45(4) : 940-947.

[14] Hayakawa M, Suzuki K, Saito H et al. Differences in cell viabilities of phytoplankton between spring and late summer in the northwest Pacific Ocean. Journal of Experimental Marine Biology and Ecology, 2008, 360(2) : 63-70.

[15] Agustí S, Alou E, Hoyer MV et al. Cell death in lake phytoplankton communities. Freshwater Biology, 2006, 51 : 14961506. 